\title{
Global Political Economy in Context of Evolution of Political-Economic Thought
} Nikolay Eletsky

Doctor of Economic Sciences, Professor, Don State Technical University, World Economy Department, Rostov-on-Don, Russia

\begin{tabular}{|c|c|}
\hline & ABSTRACT \\
\hline $\begin{array}{l}2017 \text { Research Leap/Inovatus Services Ltd. } \\
\text { All rights reserved. } \\
\text { DOI: } 10.18775 / \text { jibrm.1849-8558.2015.22.3002 } \\
\text { URL: } \underline{\text { http://dx.doi.org/10.18775/jibrm.1849- }} \\
\underline{858.2015 .22 .3002}\end{array}$ & $\begin{array}{l}\text { Globalization of economic processes requires an adequate transformation of the economic Sciences. } \\
\text { In the modern world, the globalization of actors and results of production leads to the formation of } \\
\text { global relations of ownership and governance. It modifies the subject field of General economic } \\
\text { theory and generates the global political economy. The essence of its subject matter is the } \\
\text { relationship of the global ownership and the resulting global economic contradictions. The } \\
\text { methodological toolkit of global political economy reflects the particularities of contemporary } \\
\text { scientific knowledge due to the new phenomena of globalization. Global political economy is the } \\
\text { methodological-theoretical basis of all Sciences investigating global economic system. At the same } \\
\text { time, it is a special branch of the modern system of economic Sciences, characterizing by the spatio- } \\
\text { temporal specificity of subject matter and method. The proposed approach is an alternative to the } \\
\text { common preceding scientific interpretations of global political economy as, in fact, the international } \\
\text { economic politology. }\end{array}$ \\
\hline
\end{tabular}

\section{Introduction}

The essential parameters of the economic processes of the modern world are determined by the factors and patterns of globalization, affecting all the main sides, elements and qualities of objective of social processes and their subjective reflections in the sphere of scientific knowledge. In the system of economic sciences, it's manifesting in the modification of the subject of the general economic theory and different branches of special economic disciplines. There emerge new areas of economic science, reflecting the intrinsic qualities, dependencies, and regularities of the new phenomena of economic reality posed by economic globalization.

In the system of modern world economy, it takes place "inversion" of dominance of domestic and foreign economic dependencies and regularities. Domestic economic processes lose their inherent for many preceding centuries and millennia quality of the primary over the foreign ones. Earlier the "points of growth" of world economic civilization were formed on localized areas in separate countries or regions, afterwards they spatial spread, conquering and displacing by competition historically preceding economic structures and systems, which either destroyed or transformed into marginal forms of activity in the background of the quantitatively and qualitatively dominant new economic models. Similar processes can be also observed today, but only with regard to the economic-geographical mechanism; in context of the substantial transformation of the mode of production, where the key important fact is that the primal-essential regularities of occurrence and functioning of a new mode of production are originally formed on the global level. Consequently, the substantive side of this method of production can be defined as globally-informational one. The primacy of the global regularities and the derived, secondary nature of economic interactions on the descending levels of social organization distinguish the contemporary global mode of production from the preceding trends of the genesis of globalization (Gilpin, 2001). In the system of international competition, it leads to the fact that essential importance gets the competition between countries and firms not in relation to some goods offered on the world market, but in relation to the place occupied in the global added value chains. Under the conditions of formation of information production and knowledge-based economy, the key importance becomes the control over the links of these chains, which provide scientific design and innovative options for new products.

The manifestation of the globalization trends in the functioning of international economic relations and particularly in the mechanisms of the world market is the object of study of many branches of modern world economic science. Herewith the subject of special economic sciences correlated with the level of regularities of the economic mechanism. As for research into the causes, necessity, essence, contradictions and prospects of the processes, transforming the social nature of modern economic civilization, - this kind of study is possible only in the subject field of general economic theory, performing the function of "philosophy of economy" (Global Political Economy..., 2008; Global Political Economy: Contemporary theories..., 2013; Issues and Actors..., 2017; Cohn, 2016).

\section{Methodology: Essence of the Subject Determination of the} Political-Economic Approach to the Study of Reality

The development of the economic system of society at a certain stage of this development made possible and necessary a holistic, generalized characteristics of this system within the framework of some concepts and scientific works. Researches of classics of political economy focused on the study of "the wealth of society generally", had universal character; works of J.Steuart, A. Smith, J.-B.Say, J.S. Mill can be defined as "summa oeconomia" (if using the terminology of the medieval tradition) or 
"encyclopedia of economic sciences" (in the terminology of the Enlightenment). However, this universalism had historical ultimacy both in aspect of the objective economic system development and in context of the scientific knowledge differentiation, reflecting the increasing complexity and differentiation of economic practices. Already D. Ricardo noted, in a famous letter to T. Malthus: "Political Economy, you think, is an enquiry into the nature and causes of wealth - I think it should rather be called an enquiry into the laws which determine the division of produce of industry amongst the classes that concur in its formation" (Ricardo, 2005). Meanwhile, objective logic and causality of the economic relations between members of society are that the distribution of labour results due to the distribution of factors of production; in turn, the distribution of factors of production - isn't that other, as the system of relations of ownership on these factors. Thus, we can assume that starting with David Ricardo, it begins the exarticulation of the political-economic aspect from the universal economic-theoretical knowledge, and this exarticulation is due to the correlation of the subject matter of political-economy studies with relations of ownership.

This approach was then circumstantially elaborated by K. Marx and subsequent Marxist tradition of XIX-XXI centuries. "It is always the direct relationship of the owners of the conditions of production to the direct producers - a relation always naturally corresponding to a definite stage in the development of the methods of labour and thereby its social productivity - which reveals the innermost secret, the hidden basis of the entire social structure and with it the political form of the relation of sovereignty and dependence, in short, the corresponding specific form of the state" (K. Marx. Capital, v.3. - Marx, 2005).

On the other hand, the emergence of the marginalistic discourse and neoclassical paradigm, based on it, had moved the center of gravity of the theoretical analysis on the problem of pricing and, in a broader context, on the problems of a market economic mechanism. It made possible to significantly deepen the analysis of market economic practice, but, at the same time, transformed the contents of the theoretical studies in the direction of specific economic knowledge, limiting or even eliminating the politico-economic aspect of these studies. Thus, these studies have lost the status of a General economic theory; focusing on the questions "how what and for whom to produce", the representatives of this scientific direction left aside the key for the General economic theory question "why" - why the economic systems occur, develop and replace each other, what are the essential features and contradictions of these systems. Not accidentally, the founders of the neoclassical tradition W. Jevons and A. Marshall proposed to change the name of the General economic theory instead of the term "political economy "they offered a "neutral" term "Economics". Meanwhile, in the times of A. Montchrestien term "political" was used in the context of the ancient Greek concept of "Polis", i.e.in relation to the current terminological convention, this meant a focus on the study of economic relations in scales of the State, or even of social system generally, not only of political relations in the modern sense of the word. For the representatives of early political economy, "political" or "social" aspect of the analysis was a form of overcoming the ancient tradition that stems from Xenophon and Aristotle, who understood "economy" as a science that studies the laws of "oikos" - separately existing, predominantly natural, non-market economic unit.

Unilateralism and asocial bias of neoclassical interpretation of the subject of general economic theory era, as it is known, criticized by the representatives of institutionalism. The early institutionalists noted the wrongness of reducing the theoretical economic research to the issue of "the point, sliding along the curves of supply and demand" and the nature of the economic entity- to "calculator of pleasures and deprivation". Neoinstitutionalism chose the property rights as the most important area of its research, considering the traditional political-economic problematics in the context of the wider spectrum of social interactions.

Thus, the subject matter certainty of the political-economic approach can be defined in the context of the "basic question" (or "principle problem", "fundamental issue") of the science -the question of ownership, of the ownership relations conformity to the task of increasing efficiency of economic system. Based on the analysis of the relationship between workers and owners about the factors of production, political-economic approach further develops and concretizes the research of system of production relations, including forms of economic relationships between different owners, taking into account historical features and functional mechanisms of the organization of different economic systems. The issue of ownership is thus the backbone basis of the political economy's subject matter in general and, along with it, defines the specifics of politicaleconomic knowledge in relation to "subject field" of other economic sciences, the number of which to the present time, in connection with ongoing differentiation, has reached several hundred names. Despite a substantial upgrade of the research object in the context of globalization, the preservation of the terminological tradition in designation of science is not only justified but also logical, since in these conditions the "subject core" of political economy remains too. The need to study the property relations has today the direct urgency. The most important essential feature of the present stage of the evolution of economic civilization is the globalization of ownership relations. Alongside, that is an objective basis for modification of the subject of political economy and the emergence of its new branch, now gradually taking a leading role in the substantive body of general economic theory, - the global political economy.

\section{Problem Statement: The Subject Matter of Political Economy in the Spatio-Temporal Coordinates}

High dynamism and uncertainty of the development vectors of modern civilization have raised the issue of the spatio-temporal characteristics of political-economic models, which reflect, by means of mental abstractions, the essential features and laws of development of objective economic systems. Simplifying the question, we can formulate it as follows: what the time (epoch) and space relate to those or other politicaleconomic concepts and theoretical systems? The logic of the analysis further leads on to the need to identify the relationship between the abstract conditional relativistic social time and space of the theoretical models, on the one hand, and real physical time and geographical territory of the functioning of actual economic systems, on the other.

History of political economy shows different options for the spatialtemporal "binding" of theoretical models to the socio-economic practice. Scientific directions, schools, and researchers, guided by the methodology of the concept of "natural order", with attribute for it nonhistorical axiomatics, relate (often implicit) temporal determinacy of their models with abstract "time of ideal". Economic systems, located outside the area of localization of the natural, in their opinion, economic order, either are not analyzing or are interpreting as insignificant or as the subject of transformation, in some indefinite future, in the direction of approach to the same "natural order". The previous development of economic systems, in the context of this methodological paradigm, is also presented as unimportant, because everything that happened in the past, appears only as a non-essential "preparatory phase" for approval of the "true", "genuine", "correct" natural economic order. This approach was characteristic for mercantilism, for leading representatives of the classical 
school of political economy, for marginalism and neoclassicism; today, the same approach continues its guide being for many areas of the selfproclaimed "mainstream". Such the most well-known examples of this embodiment of the spatio-temporal positioning of political-economic models are the teachings of F. Quesnay about the "sick" and "healthy" state of economic organism, and theoretical system of D. Ricardo ( The bourgeois form of labour is regarded by Ricardo as the eternal natural form of social labour. Ricardo's primitive fisherman and primitive hunter are from the outset owners of commodities who exchange their fish and game in proportion to the labour-time which is materialized in these exchange-values. On this occasion, he slips into the anachronism of allowing the primitive fisherman and hunter to calculate the value of their implements in accordance with the annuity tables used on the London Stock Exchange in 1817. Apart from bourgeois society, the only social system with which Ricardo was acquainted seems to have been the "parallelograms of Mr. Owen» - K. Marx. Critique of Political Economy. - Marx, 2005).

Another kind of -q-+unhistorical abstraction in the methodology of the "natural order" is, in spirit of Hesiod's tradition, the correlation of the "time of ideal" not with modernity, but with the bygone eras, and, as a consequence, - the contraposition of the ugly present times to the perfect past, as well as the statement of the problem of rebirth in the future certain ideal forms, previously supposedly inherent in the "Golden age". It is obvious that the degree of abstraction of mental constructions, formed on a similar methodological basis, is much higher than of the concepts relating the social time of theoretical models with the present, and it's no coincidence, for example, S. Sismondi believed that political economy "sets or needs to set a goal of happiness of people". The importance of this goal, of course, is undoubted, but the same apparently can be said of almost any other science, so such degree of abstraction leads, in particular, to the erosion of subject definiteness of the scientific knowledge branches.

In contrast to the above-noted approaches, an attribute of the methodology of national-historical school was the definition of temporal and spatial vectors of the analysis as initial essential parameters of the subject of political economy; this was objectively due, firstly, to the emergence of the phenomenon of catch-up development within the market-capitalist economic system and led to the formulation of the question of the relationship between the abstract universal and the concrete-particular regularities in the historical development of individual countries and world economy as a whole. Representatives of the historical school explicitly emphasized the dependence of the contemporary state of economic systems on the previous evolution of these systems, and linked the tasks of the future development of lagging regions to the mechanisms of overcoming the backlog and, as a consequence, the inclusion in the spatial area of the functioning of the avant-garde economic systems. The rationale for the role of spatio-temporal vectors of analysis as attributes of the essential certainty of the subject of political economy made the everlasting scientific importance of the contribution of F. List and historical school in the development of the world political economy; and it's quite natural that representatives of just this school explicitly recognized the need to create a political economy of the present and the future (Hildebrand, 2006). And although the extreme settings of the "new historical school" were subjected, during the "debate on method", convincing criticism by the leaders of marginalism - C. Menger noted the obvious inadequacy of converting political economy to "the science about variety, depending on time and place, "empirical laws" (observed regularities in the sequence) of economic phenomena" however, the proven by historical school spatial-temporal attributiveness of the subject of political economy, will have not only retrospectivelyscientific, but also directly-actual methodological importance until, firstly, the issue of "catching up development" will be relevant and, secondly, the instrumentation concepts of "path dependence" will develop.

Marxist phase in the development of political economy characterized by a radical deepening and comprehensive specification of the spatiotemporal parameters of the theoretical modeling of economic systems. The Marxist concept of the natural historical process, the analysis of the dialectics of general and special economic laws can be considered as a social-science interpretation of the principles of actualism, which applying to natural processes were already developed by representatives of natural sciences (J. Hutton: "the Present is the key to the Future"; Ch. Lyell: "the Present is the key to the Past" - K. Marx: "human anatomy is the key to the anatomy of the monkey"). In the substantive case of the concepts of K. Marx and F. Engels, there quantitatively dominate the theoretical models of their contemporary state of the economic system of the avant-garde countries, especially England, but this state is considered as a result of the natural-historical process of development of the preceding economic forms and is based on the concepts of historical materialism, theories of modes of production and socio-economic formations. Actual theoretical model of the capitalist mode of production spatially correlated by Karl Marx mainly with a geographical area of British capitalism, but given the fact that "the country that is more developed industrially only shows, to the less developed, the image of its own future" (K. Marx. Capital, v. 1. Preface. - Marx, 2005). At the same time, the "super task" of the analysis was that, based on exhaustive identification of essence and regularities of the functioning of actual economic system, to model in theory its future evolution and to provide prognostic characteristics of basic essential traits of the future mode of production. In this context, the temporal vector of analysis aimed at the future, and, simultaneously, evaluation of modernity from the point of view of the mentally modeled future implicitly constitute the main feature of the methodology of K. Marx and determine the content characteristics and assessments of the present. Theoretical modeling of the past and present is carried out by means of domination of the circumstantially elaborated positive approach, at that time as the predictive models of the future drastically increase the installation of normativity. In conditions of the marked rating of modernity through the "glimpse of the future" it imposes a tangible imprint of normativity also to the study of current economic forms.

To an even greater extent the impact of normative settings, determined by predictive models of the future, on a positive analysis of the past and present can be traced in the theoretical elaborations of bolshevism, and, above all, in the works of V. I. Lenin. Analysis of prior development of capitalism in Russia and the monopoly stage of world capitalism was performed with the dominance of the positive method, but, since the assessment of monopoly capitalism as the eve of socialist revolution and, especially, while formation the theoretical models of the socialist economy, normative "view of the future" becomes the dominant. Herewith the futuristic normativity had not become an obstacle for the scientific status of theoretical models. The development of today's China, west-european countries of "functional socialism", the practice of "social market economy" and "social state" in many countries demonstrate the truth of the key ideas of the theory of the mixed economy, modeled on the concept of the NEP ("New Economic Policy").

There are no scientific grounds for rejection of the theoretical estimates of the post-market stage of economic civilization, albeit in the context of 
a much longer time interval. It's quite obvious that the current trends of transformation of the social nature of economic relationships, especially due to informational-financial globalization of the production costs accounting, demonstrate the growing formalization of commodity-money mechanisms of interaction of economic agents and rising role of planregulating forms of economic processes on macro-, meso- and microlevels. Another thing is that the attempt of formation of the post-market economy through the practices of "war communism", as in the whole practice of socialist transformations in the conditions when capitalism in Russia not only didn't realize the inherent potential of the development of the productive forces but, in essence, only begun its evolution, was clearly premature. From the point of view of marxist theory this attempt was in clear contradiction with the fundamental postulates of historical materialism that "no social order is ever destroyed before all the productive forces for which it is developed sufficiently" (K. Marx. Preface to the Critique of Political Economy. - Marx, 2005) and "society...can neither leap over the_natural phases of its development nor remove them by decree" (K. Marx. Capital, v. 1. Preface. - Marx, 2005). In the context of the methodology of the system approach theoretical model of the "weak link in the chain of imperialism" characterized by logical validity - indeed, in conditions of increasing interdependence of the major centers of world economy at the stage of monopoly capitalism, revolution in one of the great powers could trigger a chain reaction of global socialization. But the identification of abstract social time and space of the "weak link" model with specific Russian realities of the early twentieth century was clearly erroneous.

The subsequent development of the economy of avant-garde countries in the twentieth century confirmed that capitalism as a socio-economic system is the adequate social shell of industrialism and that on the industrial technological base there are possible only fragmentary elements of socialization. As for the systemic post-capitalist transformations - they involve qualitative transformation of productive forces and their transition to the postindustrial stage of development.

\section{Analysis of the Results: Particularities of Subject Matter and Method of the Global Political Economy}

\subsection{The specifics of the subject matter of the global political economy}

The content and structure of the subject of the global political economy are determined by the objective logic of functioning and development of economic system of society in conditions of globalization (McGrew, 2008). The global transformation of ownership relations is due to the globalization of the productive forces, that requires studying the influence of factors and mechanisms of modification of the modern technological base on the productive relations system. The genesis of a new quality of this system core - globalizing relations of ownership - is a long and diverse by levels and forms of manifestation, controversial process. Adequately to this objective logic, the study of the stages of the evolution, forms of manifestation and contradictions of the development of global ownership determines the formation of relevant sections and elements of the subject of global political economy. However, strictly speaking, on the planetary level the relationships of global property today haven't yet emerged as a holistic system, there is only the formation of this system, therefore, given current realities, it is more correct to speak not of a global, but of the globalizing ownership (Eletsky, 2016).

Corresponding to the classic tradition, interpretation of the main issue of political economy as a problem of ownership identifies the systemic subject definiteness of global political economy as the science of the genesis, content, and structure of global relations of ownership.
Constituting an essential basis of the subject of global political economy, the actualizing question of global ownership is structured further in the elements of science content through studies of the mechanisms of global economic governance and the realizing of interests of the global interactions' actors (Ardalan, 2010). Thus, the status of the global political economy is determined not as the "sub-discipline", but as a methodological-theoretical base of the entire system of economic sciences.

Globalization of ownership relations has a plurality of preconditions and forms of genesis, variability of spatio-temporal and functional forms of implementation. The key importance, in line with the general logic of political-economic discourse, belongs to the globalization of the productive forces (Thun, 2008). The global-informational mode of production, based on the information resources and forms of wealth, is originally characterized by global scales and mechanisms of economic activities. Information factors of production and forms of wealth genetically embody qualities of universality, which receive organizational and economic forms of embodiment in mechanisms of global governance, attribute to them. Alongside this, the new mode of production cannot arise except on the basis of the preceding, and for a sufficiently long historical interval coexists with him, relying on its resources and gradually subordinating and transforming the previous technological and socio-economic elements, settings, and structures of the production process. Trends of global informatization and neoindustrialization are dialectically interrelated, that reflects the characteristics of the transition state of the productive forces when the development of industrial technology in modern industries is possible only by means of the globalizing informational-communication technologies and mechanisms of economic governance. The globalization of economic management reflects the contradictory interaction of the latest communication elements of the productive forces of the information society and the need for regulation, centralized in planetary scale, of use declining traditional production resources (Global Economic Governance Programme, 2017).

In recent decades, there emerged clear shapes of the genesis and establishment of global ownership, related to the direct use of various forms of resources on a global scale. The direct recognition of certain objects as property of all mankind and the legal sanctioning of such recognition are expanded in the form of treaties between the major actors of the global interactions with simultaneous or subsequent accession to these agreements of the majority of other subjects of international relations. The most famous examples of such a mechanism are the system of agreements on the regime of use of shared resources of the World Ocean, the Antarctic Treaty, the Outer Space Treaties, agreements to protect the global environment. The subjects of such treaties or agreements usually are the States, while in some cases an additional factor of international legitimacy is the conclusion of agreements under the auspices or with the participation of recognized global organizations, primarily, UN.

In contrast to the relations regulated by the international treaties expressly defining certain objects of global significance as a heritage of all mankind, technically more complex and indirect mechanisms for the formation the global ownership arise when negotiating agreements with functional or branch specificities. The activities of the global industry structures (e.g., OPEC and other similar) show the dynamics of the dialectics of the formation of the global ownership and mechanisms of its interaction, at the stage of formation, with other, historically previous and socially descending, proprietary relationships. Elements of the actual use 
of resource as the global ones tricky combined with the assignment of revenues at public and private levels.

The manifestation of the transitional nature of economic relations in the process of the formation of global property can be observed also in the activities of the largest TNCs, transforming into a Global Corporations (GCs), and intercorporate alliances. These corporations carry out the assignment of a particular type of resources and the production of certain types of products on a global scale. They also set the prices of the world market and the criteria of profitability in the relevant sectors and subsectors of the world economy, the establishment the technological and consumer standards, conduct the globally significant scientific developments and determine strategic directions of the global development. Along with that, the assignment of income is undertaken by these corporations on the basis of traditional principles and mechanisms of private property; the processes of global and private-corporative assignment of income are equated.

In the "new economy" the role of the main resources and the main forms of wealth passes to the phenomena of informational nature; both objective and subjective structure of ownership relations are changing. Meanwhile, in the early stages of a new method of production, the impact of traditional forms of realization of property that existed in the previous era, remains, in this connection, mechanisms for the protection of the incomes of owners of information resources and, in particular, intellectual property rights are the subject of developing. However, as the development and strengthening of the role of information forms of wealth, it becomes more and more obvious the qualitatively new nature of these social forms and, above all, the nature of the information as a universal resource and wealth, "trickle-down" character of the information, the universality of its distribution, application and use (Young, 2006). The possibility of free use of huge arrays of the information, contained in global information networks, and use free or for a nominal fee, reflects a new social phenomenon - the emergence of the global system of property on information with the identification of all mankind and all the descending levels of social subjectivity, up to the individual person, as subjects of ownership.

Thus, the subject specificity of the global political economy is determined by the tasks of investigation the objectively emerging global property relations and connected with its genesis global contradictions due to the impossibility of "instantaneous" emergence of the social system in established and expanded shape. New social phenomena in the process of their genesis and evolution initially originate and operate within and through the prior, previously formed social shells and mechanisms. An important fact is also the immaturity of the object-subject structure global property. Abstract concepts of global resources and wealth as objects, and all mankind as the subject of global ownership of the achieved level of the development of civilization relate to the realities of considerable socio-economic heterogeneity and hierarchy of the modern world and the confrontation between private economic interests of different levels and forms - to the interests of humanity. But the further development of relations of the global ownership and adequate system of global economic governance, the implementation of their own internal intrinsic social nature implies a complete realization and achievement of all humanity's interests and corresponding overcoming the limitations due to the initial dependence of emerging institutions of global governance on private economic interests.

The conceptions of the global political economy theoretically model the processes, characterized by global scale in terms of spatial parameters, and focused on temporary vector from today to the future state of the world ownership system, that will ensure implementation of the economic interests of all humanity as an integrative subject of the assignment of production resources and consumer goods. The historical interval of the formation, the quantitative expansion and qualitative improvement of the world of ownership, resolution of contradictions between modifying actors of the world of property and subjects of descending social levels of ownership relations is the interval of preservation by general economic theory the political-economic quality in its new historical modus of the global political economy.

The essence of property relations manifests itself in the process of its implementation. In this regard, the structural logic of the subject of the global political economy is determined by the overall objective logic of the implementation of ownership. From the point of view of the production process, the implementation of ownership is the managing it to ensure economic benefit; from the point of view of the outcome of the economic process, it's realizing in the assignment of income. Accordingly, genesis and mechanism of global economic governance become an essential element of the subject of the global political economy.

Herewith, such structural and hierarchical features of global governance in today's global capitalism, as the priority of interests internally deeply integrated global finance capital and the transformation of the State apparatus of even the largest countries to the committee on administration of personifying this capital global financial oligarchy, are becoming more apparent. A lot of new types of socio-economic contradictions arise both within individual countries and in international economic relations (Wade, 2008; Odezah, 2016).

The transition from monopolistic and state-monopolistic capitalism to the stage of global finance capital has become the socio-economic shell of the transition from the late-industrial technological mode of production to the early stages of the global-informational one. But as its further development, more and more important intrinsic objective of the research program of the global political economy will become the analysis of the emerging elements of post-capitalist socio-economic structures and their subsequent system integration in the direction of the global community.

From the point of view of tier structure, the system of economic relations involves two main levels: primary, deep, essential level of ownership relations, and a secondary, outer - level of manifestation of the essence of ownership in the relations of the economic mechanism. The second one determines the contents of object of specific economic disciplines, but the formation of theoretical-methodological foundations of their subject is the task of political economy and, thus, one of the sides of its subject. In the subject structure of the global political economy, it's reflected through the need of analysis of the world market mechanisms, international trade and global financial system as the main forms of manifestation and realization of the globalizing relations of ownership at the level of world economic mechanism.

One of the attributes of the movement of social relations is an organizational component. Accordingly, the analysis of the implementation of property relations requires the identification of organizational forms of this implementation. In the modern world, it arises the process of intensive formation of a variety of global organizational structures, including the structures providing organizational parameters of formation and development of globalizing ownership, resolution of conflicts, generated by its genesis. The most 
important of these include the contradictions between the organizational structures of global governance and the structures that ensure the sovereignty of national States (Hay, 2008), between the globalizing apparatus of TNCs and other global, regional and national organizational structures.

Objective dialectics of basic and superstructure relationship gives rise to the interconnection and interdependence of economic realization of property relations and superstructure's ensure its implementation through political, legal and ideological instruments (Authority in the Global Political Economy..., 2010). The formation of a global component of these tools is one of the key directions of transformation of modern society. The analysis of the mutual conditionality of basic and superstructure tools of realization of global ownership is also, in this regard, a mandatory aspect of the subject of global political economy and requires the involvement of the results of neoinstitutional research as an empirical basis for the political-economic generalizations.

\subsection{Features of the method of the global political economy}

Global political economy, like any other science, uses universal methods of thinking and general scientific methods of knowledge, fleshed out by specifics of the subject of theoretical-economic research. Alongside this, its method has features, due both to the novelty of the object of cognition, and modern trends of the development of general scientific methodology. Initial and general methodological setting for global political economy is the setting of comprehension of the essence of processes and phenomena occurring in the system of the world economy in conditions of globalization. The comprehension of the essence involves identifying regularities that embody the essential underlying causal relations in the functioning and development of world economic system. Axiomatic setup for the cognition entity includes a representation of hierarchically-tiered structuring of the processes of economic practices in the global economy, which requires the detection of objective trends and patterns behind the flux of observable phenomena, facts and events, diverse and contradictory in their movement. The detection of regularities is possible by a generalization of the entire array of empirically observed facts, their grouping and logical sequencing with subsequent structuring. This is achieved through the method of abstraction, by creation a hierarchical system of causal dependencies that allow moving from the external, superficial appearances to deeper levels of theoretical modeling of the necessary internal laws.

Articulated installation on the knowledge of essence and laws would be of a trivial nature (it's obvious that the task of any science is to cognize the essence of its object), if in the last decades it wasn't the widespread of the methodology of "postmodernism" with an attribute inherent "antiessentialism", i.e. a fundamental rejection of the concept of the entity, of recognizing the distinction between the essence and the external forms of its manifestation. The task of the science in this approach comes down to a situational external reflection of the kaleidoscopic flow of facts, each of which is treated as a self-sufficient, essentially equal to anyone else. Accordingly, the notion of regularity disappears from the totality of the phenomena of the mental reflection of the objective world, including from the system of scientific thinking. "There are nearly disappeared the notions of "materialism", "idealism", "rationalism," "irrationality," "sophistry", "eclecticism", "dialectic," "contradiction", "essence", "phenomenon", "opportunity", "reality", "necessity", "accident", "true" "false" - in short, all those philosophical terms and categories, without which the philosophy is inconceivable... It also lost all sorts of scientific criteria and conclusiveness» (Gobozov, 2015).
From a theoretical point of view, anti-essential "strangeness" of postmodernism could be classified as a kind of now numerous pseudoscientific fictions, curiosities, which are beyond of the modern scientific knowledge. However, the problem is greatly complicated by the fact that, becoming a fashionable trend, a postmodern installation, as supposedly embodying the new achievements of scientific methodology, can influence the mentality of the politicians and other agents of social power. But what could be the practical results of the activities of the policy, perceived such methodological postulates: "is it, indeed, the need of being tasked with such challenges as establishing the content of epoch? Is there such a thing?", and thinking that answering these questions is the task "feasible is that only God himself"? (World Economy..., 1990). The inevitable consequence of the abandonment of the search for the essence of social phenomena is also becoming the rejection of goal-setting and planning of the practical activities. After all, if the era doesn't have the content, then there is no need to comprehend your position and your goals within the framework of this era - it's just enough "to go with the flow", passively sensing the external and independent from the social subject sequence of events and not related to each other paintings of the surrounding world.

It's easy to understand that social facilities (the States, scientific and economic structures, regional and international organizations), don't seek to know the essence of what is happening in the world, become, in the context of globalization, not the social actors but passive objects of manipulations, performed by centres of global influence. These centres, on the one hand, spread illusions about the alleged "modernity" and "depth" of postmodern approaches; they advertise the respective authors and their publications, and, on the other, themselves don't abandon scientific research of the globalization's patterns and mechanisms to achieve their goals in view the changes happening in the world under globalization.

Once more consequence of the proliferation of the postmodern paradigm is an idea of the alleged normality of incompetence, amateurism in all spheres of human activities, including the sphere of economic management. In fact - if there is no fundamental difference between externally observed empirical facts and essence of economic processes, then there is no objective basis for differences between activity, including management actions, of any casual participant of economic processes, on the one hand, and of a professional manager, on the other. "In the epoch of postmodernism, everything is simplified, primitivized: economy, politics, culture, spiritual work, in general, do not seem to be as complex, demanding and hard work, but as something that everyone can do. Look at the economy itself. Clearly, in order to engage in economic activity or to lead economic institutions some special knowledge is required. But now, it turns out, it isn't necessary... Incompetent, mediocre people on high economic positions simplify the most complex processes of production activities that are the basis of all human activity" (Gobozov, 2015).

Additional factors hindering the cognition of scientific truth in the study of economic processes become at present the features of thinking caused by the fragmentary incoherent, heterogeneous and multilevel data presented in the flow of modern communication systems. A large array of these data creates the illusion of high awareness and equitable neighborhood of the facts of "news feed" - a sensation of the equivalence of these facts. Meanwhile, without comprehension, the facts through the analytical abstraction and tier differentiation, the flow of heterogeneous empirical information acquiring excessive in nature, leads not to the identifying the truth, but rather to its distortion and turning into something 
inessential. Most of the negative practical consequences of this so-called "twitter-mindset" are manifest when it becomes inherent to the political and economic leaders.

The need for understanding the essence of processes of globalization of ownership, and on this basis - the entire system of economic relations, also leads to the actualization of the special role of such parties and elements of the method of global political economy, as the principles of dialectics, system approach, holism, and synergetics.

A dialectical approach requires consideration of the globalization of economic relations as a developing contradictory process, passing a series of stages, combining periods of relatively stable, steady and gradual evolution with drastic changes, quality jumps, intervals of uncertainty and destabilization. Gradual maturation and accumulation of quantitative changes in the technological, institutional and socio-economic realms, reaching the limiting, in some measure, condition, lead to qualitative transformations of the system of the world economy. The origin, development, and resolution of global contradictions contribute to the emergence and diffusion of new, more effective forms of international economic relations. New global institutional and socio-economic structures are formed for regulation of contradictions and their resolution. The dialectical approach reflects, in addition, the objective possibility of the diversity of manifestation forms of a single entity. In particular, the essence of globalization can also manifest itself in different forms and is especially important for individual States and civilizational systems, whose interests may be with varying degrees implemented under various forms of essentially uniform processes of globalization. Of particular importance today is the fact that the americanization associated with suppression of the interests of many States, is not the only possible and universal form of globalization. The study of the mechanisms of globalization also necessarily involves the study of dialectics of its economic foundations and superstructure's (political, legal, ideological) aspects.

There is also a clear relationship between the described above principles of essentialism and the dialectics, and the methodology of the system approach. The understanding of objects of study as a system entities; the theoretical response of the system's quality; identification the "core" of the system, of its strategic elements; the hierarchical structuring of the system's tiers; analysis of the mechanisms of the system's quality distribution on all the elements, and the formation of the missing elements, mechanisms of tiers' interaction; the study of the evolution of the system, the study of relationship of its functioning and development; analysis of the contradictions of system and the ways to resolve them all of these methodological attributes of systematic approach are essential tools of scientific knowledge of the modern world economy as a system in which the processes of globalization of ownership relations are the essential system factors of transformation of international economic relations.

The principle of holism stands out as one of the actual concretization of the system approach, reflecting the mechanism of the dialectical interaction between the whole and the parts within the system. For the global political economy, it's of particular importance due to the fact that the current stage of globalization is characterized by the formation of a primary, intrinsic laws of functioning and development of world economic system initially on a planetary level. Embodying the emerging system unity and integrity of the modern world economy (and, above all, - the emergence of the globalizing property relations), these laws become the primary in comparison with the economic processes occurring at all the descending levels of social structure. This primacy is implemented both in the downward territorial levels of the world economy (transcontinental and regional associations, individual States), and in its functional, organizational and industry structures (international institutions, organizations, and firms). Even leading States and their associations, the institutions of global governance and the world's leading TNCs are objectively subordinated in their activity to the prime regularities of globalization and implement these laws through their activities. This is the phenomenon that distinguishes the modern globalization (or, in some interpretations, its current stage) from the preceding stages of world economy development, when the primary laws have initially developed within a geographically and functionally limited areas, and then spread to the rest of the world due to the higher efficiency of the economic phenomena encountered in these areas.

Methodology of synergetics focuses theoretical research on the necessity of studying economic globalization as a self-organizing process. Objective factors and mechanisms of self-organization of the globalizing economy act independently of subjective desires and preferences. Moreover - practical actions of anti- or alterglobalists can turn into factors of approximation of the self-organizing globalization to the attractor states in the same way as the actions of its conscious supporters. The most important aspect of the significance of the synergetic approach today is understanding the responsibility of the decisions and actions of social actors in conditions of the bifurcation alternatives. At bifurcation points, there are the equal possibilities of implementing different alternatives of the subsequent movements, but this equality combined with the subsequent divergence of the trajectories of the systems movement; in some cases - with very large discrepancy, until the mutually exclusive forms of alternatives. So, there were sufficient objective prerequisites for different options for the development of the Soviet Union in the late twentieth century. Some of them could lead to another mode of modern world, and there would be other forms of manifestation of the essential patterns of globalization. In fact, however, it implemented a different option caused by a combination of random and originally not inevitable factors, specific to the point of bifurcation.

Feature of the functioning of the system in the approximation of the bifurcation points is also the increased degree of uncertainty of its status and development prospects. At the present stage of globalization, the world economy took the form of "economy of uncertainty". Its essential attribute is the necessity of making economic decisions on the basis of the current incomplete, inaccurate and limited information. Furthermore, the consequences of these decisions will manifest themselves in the process of continuous changes in external and internal conditions of activity, so the final effects may differ significantly from the original objectives, and in some cases contradict them. Even the formal achievement of the original goals, can lose meaning and lead to a meaningful opposite effect if within the period of time required to achieve the objective, external economic and social environment had undergone essential qualitative modifications. This requires continuous monitoring and adjustment of goals of economic activity and means of their achievement and essentially distinguishes the modern economy not only from the traditional economic systems with a constant reproduction of the same assumptions and results but also from the routine algorithms of traditional market. These objective factors contribute to the substantial increase of the role of conscious implementation of the principles of scientific methodology not only in theory but also in practice. 
5. Conclusion. Global Political Economy and the Scientific Studies of Economic Globalization

Globalization of the productive forces and relations of production constituted the objective basis of the changes in the world economic system, theoretical generalization of which became new directions in global economic science, defining as global, international political economy, geoeconomics etc. (Global Political Economy..., 2008; Global Political Economy: Contemporary theories..., 2013; Issues and Actors..., 2017). The relevance of the development of these scientific directions, including methodological aspects, is constantly increasing. At the same time, variability, vagueness, looseness of terminology and lack of generally accepted conventions reflect both the system immaturity of object and epistemological specificity of the subject of political economy on the qualitatively new stage of its evolution.

Methodological commonality of the named and other, adjacent them on problematics, areas of the world of economic science, essentially, up to now is limited by the recognition of axiomatically the principle of holism and by the understanding of the impossibility of explaining the key trends and development prospects of the global economy on the basis of previous mapping of the subject of political economy with the scales of the national state or other parts and sides of world economic system.

As for the interpretation of the subject of study, it's observed wide range of approaches, tending, in general, to the nexus of economic and political factors in global interactions, to the role of economic interests in the global power relations, as well as to the issues of efficiency of financial interactions and international trade. The fragmentation and fuzziness of the subject certainty lead to the secondariness of the role of these research directions in the paradigmatic structure of "mainstream" and to recognition them, at best, as borderline subdisciplines in the subject field of the theory of international economic relations. However, the objective role of property relations as the core of the system of productive relations determines an objective status of the world political economy as a backbone kernel of a set of economic sciences in the context of the increasing impact of globalization of ownership and economic governance on the development of the world economy.

The objective processes in the global economy also lead to transformation of the subject of the traditional for economic theory areas of micro and macroeconomics. It is evident the necessity of modifications of the models of microeconomics in view of the transformation of transnational (and in the leading sectors, global) corporations into the main modern form of primary economic link (complex) and the necessity of corresponding modification of the mechanisms of pricing, formation and distribution of global (worldwide) income and taxation.

With regard to macroeconomic concepts, their modern specification requires a transition from understanding the economic system as a phenomenon, the essential laws of which are formed within the borders of individual States, to the cognition these laws at the level of global economic system (Hay, 2008).Accordingly, the role of the main macroeconomic subject is transferred from individual State to the various international entities and to the institutions of global economic governance.

At the same time, even in the case of successful modification of the subject of micro- and macroeconomic research, their subject-level differentiation with the concepts of the global political economy will retain its character. Recorded at the empirical level trends of globalization of market relations are only the outward manifestation of the deep transformation of the very essence of economic civilization, and for the system characteristics of the global cardinal changes, it isn't sufficient the toolkit of different directions of "economics", subject matter of which is correlated with the level of regularities of market economic mechanism. In general it can be noted that, besides the level differentiation with the disciplines studying the field of economic mechanism, characteristics of the subject specificity and the structural logic of the global political economy implies the concretization of its relationship to the subject fields of such disciplines as "international political economy", "geopolitical economy", "world economy", "international economic relations", "geoeconomics," "economic globalistics" and several others (Aggarwal and Dupont, 2008; Desai, 2013; Ravenhill, 2008; Review of International Political Economy, 2017; Watson, 2008; Cohn, 2016).The dynamism of the object and subject of sciences, a partial intersection of their subject fields, of objects, of levels and aspects of the analysis; the "borderline", interdisciplinary nature of many problems and the relativity of the current conventions of defining the subject specificities, inevitably lead to a ambiguity of differentiation and continuous changes of the ratio of their subject, structure and perspectives (O'Brien \& Williams, 2016). At some extent, with regard to these scientific branches, we can talk about competing for research programs and discourses.

Simultaneously, actually existing traditional conceptual and methodological approaches and research programs define the role of such disciplines as "world economy" and "international economic relations" as tools for the systematization of empirical facts, reflecting the functioning of the world economy. In fact, today's discourse of "international political economy" is close to the content of the subject matter of these sciences. It is possible to note the terminological inaccuracy of the self-named "international political economy". This interdisciplinary scientific branch, on the actual content of its subject field, is actually an "international economic politology". It explores a spectrum of, certainly, very important and topical issues, but mainly in the context of the synthesis of international politics and theories of international economics. By this approach, the political-economic problems remain in the background; moreover, it's hardly possible to recognize as the correct the interpretation of "global political economy" as applied aspect of "international political economy".

"Geo-economics" and "geopolitical economy" act as the elements of dialectical pair with "geopolitics" and, as a rule, examine the economic mechanisms to achieve geopolitical goals. "Economic globalistics" is focused on the study of the empirical regularities that are initially and primarily formed at the level of the modern whole-planetary economic system. For each of these Sciences, the political-economic approach, revealing the contents, role, and contradictions of property relations is the methodological-theoretical basis. Alongside this, being detached, generalized and systematized as a distinct research direction, this approach forms the subject of special branch of modern scientific knowledge - the global political economy.

\section{References}

- Aggarwal, V. and Dupont, C. (2008). Collaboration and CoOrdination in the Global Political Economy. Global Political Economy / ed. by John Ravenhill. New York: Oxford University Press, 67-94.

- Ardalan, K. (2010). Globalization and Global Governance: Four Paradigmatic Views. American Review of Political Economy, Vol. 8(1),6-43. 
- $\quad$ Authority in the Global Political Economy (2010) / ed. by Volker Rittberger and Martin Nettesheim. L: Palgrave. - 320 p.

- Cohn, T.H. (2016). Global Political Economy: Theory and Practice. -7 th ed. NY: Routledge. -426 p.

- Desai, R. (2013). Geopolitical Economy: After US Hegemony, Globalization and Empire. The Future of World Capitalism. London: Pluto Press, and Halifax: Fernwood Publishing. - 313 pp.

- Eletsky, N. (2016). Contradictions of Formation of the Global Economic Governance System. International Journal of Management Science and Business Administration, Vol. 2, Issue 10, 7-16.

- Gilpin, R. (2001). Global Political Economy: Understanding the International Economic Order. Princeton: Princeton University Press. - 440 pp.

- Global Economic Governance Programme (2017). Research.http://www.globaleconomicgovernance.org/research

- Global Political Economy (2008) / ed. by John Ravenhill. New York: Oxford University Press.

- Global Political Economy: Contemporary theories (2013) / 2 nd ed., ed. by Ronen Palan: Routledge, L \& NY. - 238 pp.

- Gobozov I.A.(2015).Postmodernism is the era of mediocracy. Problems of Philosophy, №12, 41-53(Translated from Russian: Вопросы философии, 2015, № 12,с. 41-53).

- Hay, C. (2008). Globalization's Impact on States. Global Political Economy / ed. by John Ravenhill. New York: Oxford University Press, 314-345.

- Hildebrand, B. (2006). Die National-Oekonomie der Gegenwart und Zukunft.http://www.worldcat.org/title/nationalokonomie-dergegenwart-und-zukunft/oclc/15350248

- Issues and Actors in the Global Political Economy (2017). http://www.academia.edu/5123463/Issues_and_Actors_in_the _Global_Political_Economy

- Marx, K. (2005). Karl Marx and Frederick Engels: Collected Works. London: Lawrence \& Wishart.

- McGrew, A. (2008). The Logics of Economic Globalization. Global Political Economy / ed. by John Ravenhill. New York: Oxford University Press, 277-313.

- O'Brien, R. \& Williams, M. (2016). Global Political Economy: Evolution and Dynamics. - 5th ed. L.: Palgrave. - 376 p.

- Odezah, S. (2016). The Paradox of the American War on Poverty. Journal of US-China Public Administration, Vol. 13, No. 1, 41-54.

- Ravenhill, J. (2008). The Study of Global Political Economy. Global Political Economy. 2nd ed. / ed. by John Ravenhill. New York: Oxford University Press, 3-26.

- Review of International Political Economy (2017). http://www.researchgate.net/journal/14664526_Review_of_International_Political_Economy

- $\quad$ Ricardo, D. (2005). The Works and Correspondence of David Ricardo / ed. Piero Sraffa with the collaboration of M.H. Dobb. Indianapolis: Liberty Fund. Vol. VII, 278-279.
- Thun, E. (2008). The Globalization of Production. Global Political Economy / ed. by John Ravenhill. New York: Oxford University Press, 346-372.

- Wade, R. (2008). Globalization, Growth, Poverty, Inequality, Resentment, and Imperialism. Global Political Economy / ed. by John Ravenhill. New York: Oxford University Press, $373-$ 409.

- Watson, M. (2008). Theoretical Traditions in Global Political Economy. Global Political Economy / ed. by John Ravenhill. New York: Oxford University Press, 27-68.

- World Economy and International Relations (1990). (Translated from Russian: Мировая экономика и международные отношения, 1990, № 5, с. 59).

- Young, G. (2006). Global Political Economy in the Information Age. L.: Gardners Books. - 397 p.Schrenk, L.P. (2006). Equityholder versus Stakeholder and Corporate Governance: Developing a Market for Morality, Business Renaissance Quarterly, 1(3).

- Stebbins, R.A. (2001). Exploratory Research in the Social Sciences. Sage University Papers Series on Qualitative Research Methods, Vol. 48. Thousand Oaks, CA: Sage, CrossRef

- Trotter, R.T. (2012). Qualitative research sample design and sample size: Resolving and unresolved issues and inferential imperatives. Preventive Medicine, 55, 398-400, $\underline{\text { CrossRef }}$ 